\title{
Proyecto La Cadena-Quevedo-La Maná. Primera síntesis modal y cronológica así como breves referencias a la cerámica del Formativo Temprano final
}

Projet La Cadena-Quevedo-La Maná. Première synthèse modale et chronologique, brèves références à la céramique de la fin du Formatif Ancien

The archaeological project of La Cadena-Quevedo-La Maná. First modal and chronological analisis of settlements and modelization of late Valdivian ceramics

Nicolas Guillaume-Gentil

\section{(2) OpenEdition Journals}

\section{Edición electrónica}

URL: http://journals.openedition.org/bifea/1813

DOI: $10.4000 /$ bifea. 1813

ISSN: 2076-5827

Editor

Institut Français d'Études Andines

Edición impresa

Fecha de publicación: 1 diciembre 2010

Paginación: 641-665

ISSN: 0303-7495

Referencia electrónica

Nicolas Guillaume-Gentil, «Proyecto La Cadena-Quevedo-La Maná. Primera síntesis modal y cronológica así como breves referencias a la cerámica del Formativo Temprano final », Bulletin de I'Institut français d'études andines [En línea], 39 (3) | 2010, Publicado el 01 junio 2011, consultado el 09 diciembre 2020. URL : http://journals.openedition.org/bifea/1813; DOI : https://doi.org/10.4000/bifea. 1813

\section{(c) $)(8)$}

Les contenus du Bulletin de l'Institut français d'études andines sont mis à disposition selon les termes de la licence Creative Commons Attribution - Pas d'Utilisation Commerciale - Pas de Modification 4.0 International. 


\title{
Proyecto La Cadena-Quevedo-La Maná. Primera síntesis modal y cronológica así como breves referencias a la cerámica del Formativo Temprano final
}

\author{
Nicolas Guillaume-Gentil
}

\begin{abstract}
Resumen
Este proyecto de invesetigación, iniciado en 1992, consiste en un aporte a la historia material y cultural poco estudiada de los piedemontes andinos occidentales del Ecuador. La zona tropical donde se han hecho las investigaciones es muy rica en nichos ecológicos y en recursos naturales. La topografía del terreno ha estimulado un poblamiento muy antiguo (al menos 6000 a. C.) y ha dado lugar a una adaptación al medio muy húmedo. El hombre edificó estructuras elevadas, tolas, que permiten desarrollarse en tales condiciones. Paso inevitable entre la Costa, la Sierra y el Oriente, el piedemonte andino se halla en el centro de las vías de comunicación que favorecen los intercambios e inducen una mezcla cultural aún difícil de evaluar. El estudio de la cerámica valora este concepto ya que revela numerosos estilos que cubren todo el periodo prehispánico. En este artículo, se presenta únicamente la cerámica del Formativo temprano.
\end{abstract}

Palabras clave: El Ecuador, tolas, cronología, modos de implantación, cerámica, Valdivia

CNRS UMR8096, Paris 1 Sorbona, Francia y Universidad de Neuchâtel, Espace Paul Vouga, CH2038 Hauterive, Suiza. E-mail: ngg@cifom.ch o nicolas.guillaume-gentil@bluewin.ch o nicolas. guillaume-gentil@rpn.ch 


\title{
Projet La Cadena-Quevedo-La Maná. Première synthèse modale et chronologique, brèves références à la céramique de la fin du Formatif Ancien
}

\begin{abstract}
Résumé
Ce projet de recherche, entamé en 1992, souhaite contribuer à l'histoire matérielle et culturelle fort peu étudiée des piémonts andins occidentaux de l'Équateur. Cette zone tropicale est riche en niches écologiques et en ressources naturelles. Sa topographie a stimulé le peuplement ancien (depuis au moins 6000 av. J.-C.), et a donné lieu à une adaptation de l'homme dans un milieu humide, I'obligeant à élaborer des structures d'habitat, tolas, permettant de vivre dans de telles conditions. Passage obligé de la Costa à la Sierra et à l'Amazonie, le piémont andin se trouve ainsi au centre des voies de communication qui favorisent les échanges et induisent un brassage culturel encore difficile à évaluer aujourd'hui. L'étude de la céramique met en valeur ce concept, car elle révèle de nombreux faciès qui couvrent l'ensemble de l'ère préhispanique. Dans cet article, seule la céramique du Formatif ancien est traitée.
\end{abstract}

Mots clés : Équateur, tolas, chronologie, modes d'implantation, céramique, Valdivia

\section{The archaeological project of La Cadena-Quevedo-La Maná. First modal and chronological analisis of settlements and modelization of late Valdivian ceramics}

\begin{abstract}
This research project started in 1992 consists in a contribution to the material and cultural history of the Andean western piedmonts of Ecuador, which has been little studied. This tropical area is rich in ecological niches and natural resources. Its topography has stimulated settlement since at least 6000 $\mathrm{BC}$, and has led to a human adaptation in wet surroundings, obliging human beings to build living structures, called tolas, which made life possible under such conditions. The movement from the coast to the highlands and Amazonia inevitably crosses the Andean piedmont which is situated in the center of the communication routes which promote exchanges and lead to a cultural intermixing that is still difficult to estimate today. The study of ceramics highlights this concept, because it reveals a great number of styles which cover the whole Prehispanic era. In this article, only the ceramics dating to the Early Formative are treated.
\end{abstract}

Key words: Ecuador, tolas, chronology, settling modes, ceramics, Valdivia

Las hipótesis emitidas sobre el poblamiento y el desarrollo de las sociedades que ocuparon el norte de la Cuenca del Guayas (fig. 1), justificaron la reanudación de las investigaciones basadas, esta vez, en el estudio estratigráfico stricto sensu. Si bien Porras (1983; 1987), Holm (1978), Echeverría (1983), Zevallos-Menéndez (1995) sugirieron la emergencia de las tolas en tiempos más lejanos (Desarrollo regional, 500/300 a. C.-500 d. C.), ningún trabajo fue verdaderamente llevado a cabo en este sector, con el fin de comprobar estas hipótesis. Los investigadores en cuestión se basaron en algunas constataciones que no encajaban con su esquema analítico y desviaron la problemática de eventuales ocupaciones más antiguas. Cuando comenzaron las excavaciones en La Cadena, se consideraba este sector 


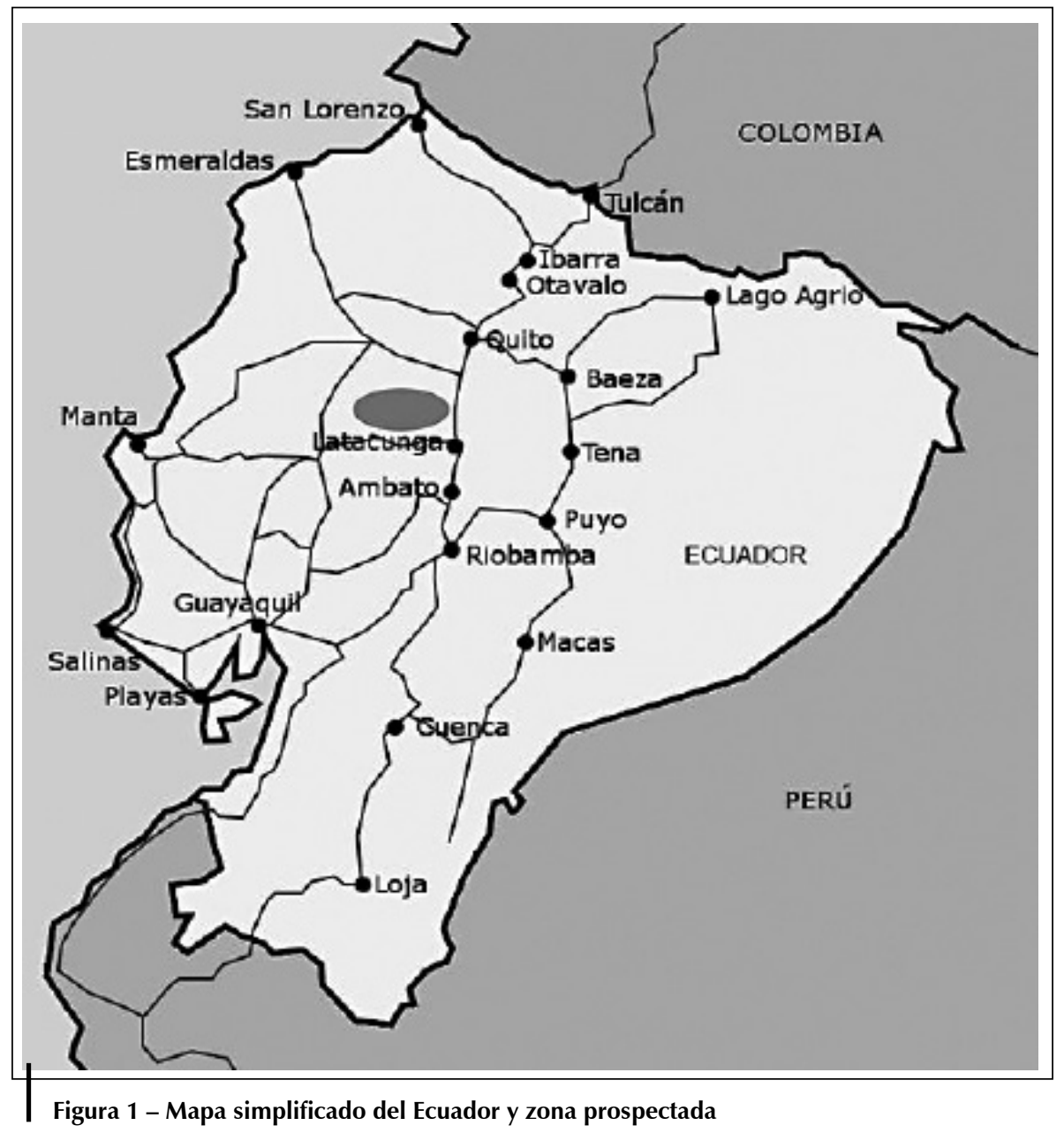

como colonizado por grupos culturales del Milagro-Quevedo (Integración 5001500 d. C.) que construían montículos artificiales cuya función era esencialmente funeraria.

La carencia de investigaciones de la investigación en esta región constituye una falta que intentamos cubrir, tanto desde el punto de vista cronológico como funcional y cultural. Los objetivos de las dos primeras campañas de excavación consistían en el establecimiento de una secuencia crono-cultural de la zona, por medio de excavaciones sistemáticas en un complejo ciertamente restringido, pero en donde la presencia de estructuras intactas, permitía proceder a cortes estratigráficos completos. Sobre esta base, se volvía posible realizar excavaciones por decapados horizontales y en niveles naturales, a fin de observar el desarrollo de los periodos de ocupación definidos previamente. 
Una segunda fase de investigación, Ilevada a cabo en dos misiones de tres meses cada una, permitió prospectar sistemáticamente la llanura del Alto Guayas, limitándonos a un área de extensión representativa, capaz de ser evaluada en el tiempo previsto para nuestro trabajo. El objetivo principal buscaba estimar el potencial arqueológico de la región, establecer un plan de distribución de los sitios en el sector escogido (fig. 2) y poner de manifiesto eventuales patrones «urbanísticos» de los agrupamientos de tolas (fig. 3).

Los resultados obtenidos en el curso de los cuatro primeros años, motivaron una reanudación de las excavaciones en un contexto diferente de inicios del proyecto. Los descubrimientos resultados de la prospección revelaron numerosas variantes estructurales de sitios, entre las cuales, tres modelos recurrentes que justificaron una prórroga de las excavaciones, apuntando a una comparación material, cronológica y funcional de los diferentes patrones arquitecturales puestos en evidencia.

Así, al término de siete campañas de investigación, el proyecto tiene la capacidad de verificar la fiabilidad de la intuición cronológica establecida por nuestros predecesores, a la vez que de aportar una visión más crítica de los datos disponibles, en función de una estrategia que contiene once puntos.

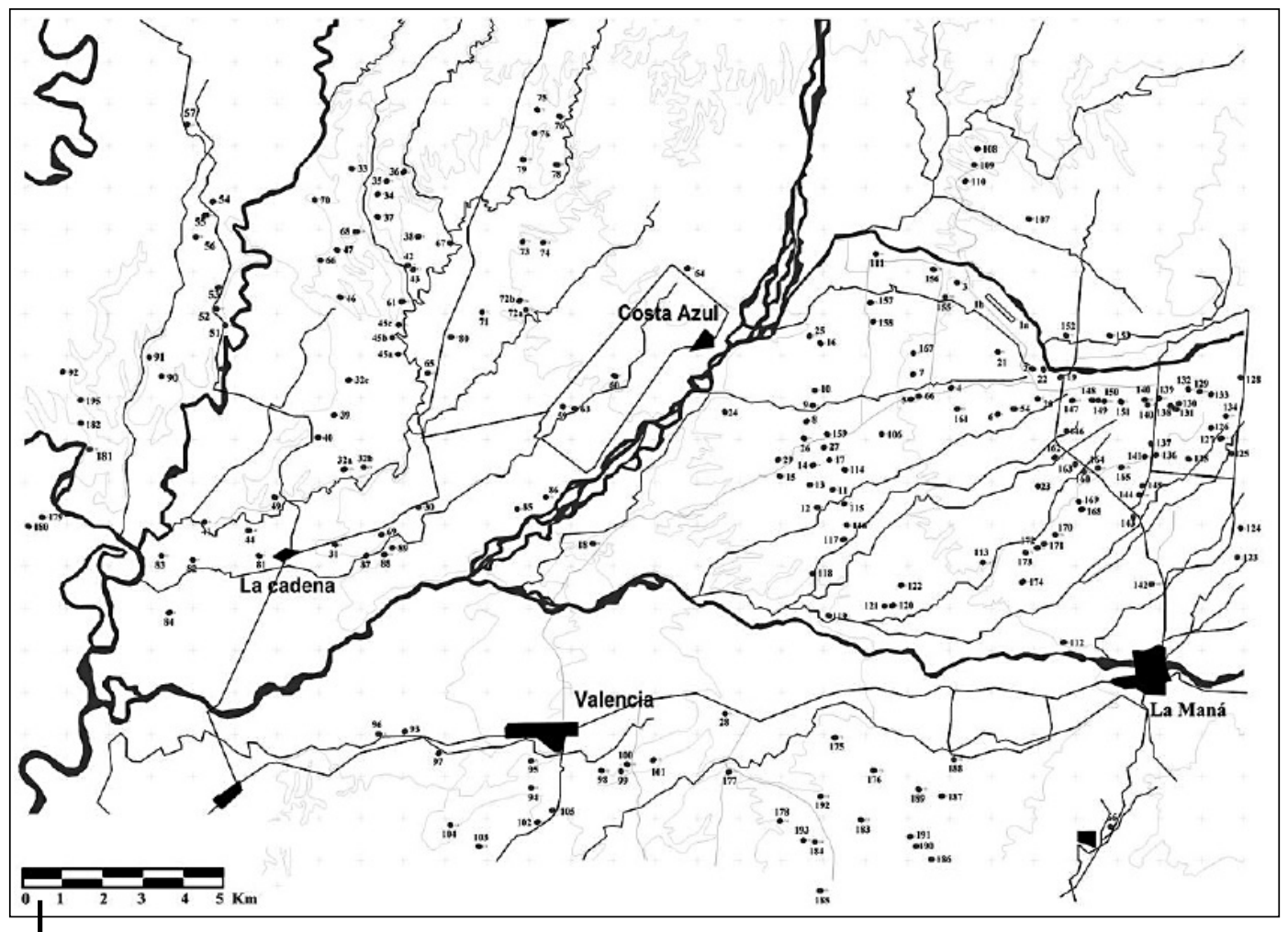

Figura 2 - Área de distribución de los sitios después de la prospección del año 2000 


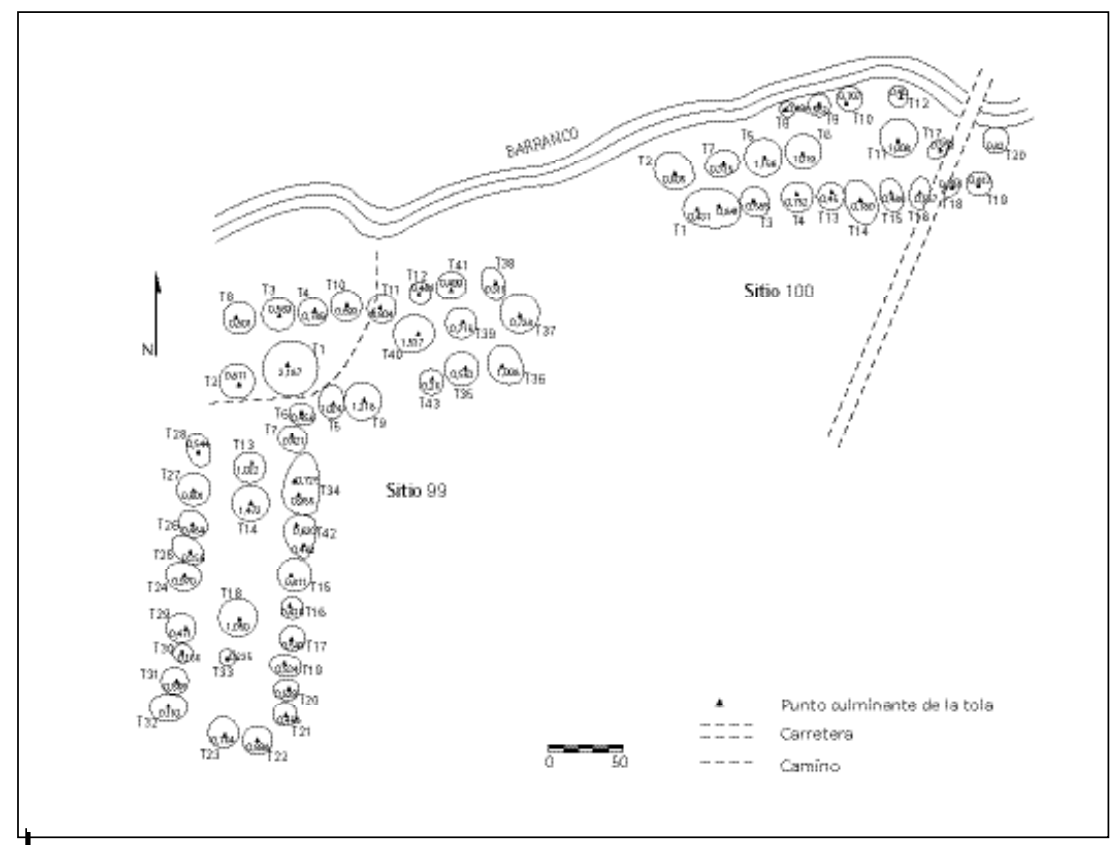

Figura 3 - Planos de los sitios 99 y 100 (escala 1/1000)

1) Evaluar el potencial arqueológico de una región poco estudiada desde el punto de vista cronológico, cuantitativo y cualitativo.

2) Entender la organización espacial de los sitios.

3) Establecer una secuencia estratigráfica lo más completa posible.

4) Situar cronológicamente la construcción de los montículos artificiales.

5) Explotar el máximo de registros disponibles para la datación (radiocarbono, termoluminiscencia, tefrocronología).

6) Proceder al análisis de materia prima a fin de determinar su procedencia y circulación.

7) Observar los cambios arquitecturales de las estructuras halladas en las tolas.

8) Proponer una síntesis sobre los modos de implantación humana en el curso de la prehistoria de la región.

9) Restituir, dentro de los límites científicos actuales, los modos de vida de las sociedades prehispánicas que se sucedieron a lo largo de la prehistoria puesta en evidencia en dicha región.

10) Crear un método de análisis de los vestigios que permita confrontar los resultados existentes con aquellos obtenidos en la misión La CadenaQuevedo-La Maná.

11) Presentar una tipocronología de la cerámica descubierta durante las excavaciones, matizar y precisar, estilísticamente y cronológicamente, el marco cultural actualmente en vigor en el Ecuador. 
La estrategia aplicada reposaba en un cierto número de preguntas que habían surgido desde el inicio de los trabajos y que legitimaban tan larga búsqueda de informaciones:

- ¿cuándo comienza la construcción de montículos artificiales?

- a imagen de las teorías precedentes, originadas principalmente en investigaciones en los Andes, ¿tiene ésta que ver únicamente con ritos funerarios?

- ¿se trata de una práctica cuyas diferencias topográficas y morfológicas obedecen a factores cronológicos y/o funcionales (hábitat, artesanía)?

- ¿cumple una tola la misma función en el transcurso de sus refacciones?

- ¿existe alguna articulación funcional sincrónica entre los montículos de un mismo sitio? Y iqué hay del punto de vista diacrónico?

- ¿las particularidades observadas en la cuenca alta del Guayas son exclusivamente propias de esta región, o aparecen recurrencias en una porción geográfica más extensa?

- ¿qué tipo(s) de relación mantienen las sociedades de las llanuras con los grupos de otras regiones?

- ¿qué ventajas económicas (transportes, desplazamientos humanos, intercambios, etc.) favorece la red hidrográfica?

Debido a la acción presentada, se puede constatar que el proyecto «La CadenaQuevedo-La Maná» se inscribe en la misma perspectiva que aquella establecida por las corrientes de la arqueología contemporánea, tendiendo a la constitución de una base de datos fundamentada en los ejes reveladores (espacio, tiempo, transformación y cuestionamiento, etc.) de pueblos que no han dejado huella escrita de su presencia. El equipo de la SLSA ha comenzado una extensa investigación en un sector rico en informaciones culturales y socioeconómicas, con el fin de reestructurar y redefinir la cronología de los grupos culturales que han ocupado estos territorios, a fin de rever, o sino redistribuir la repartición territorial de cada uno de ellos, y en la medida de lo posible, restituir los modos de vida de aquellas sociedades.

Los resultados obtenidos durante el transcurso del proyecto muestran que valía la pena mantenerlo, cualesquiera que fueran las dificultades halladas en el camino. Al término de este trabajo, constatamos que un paso importante se ha dado en el campo de la comprensión del fenómeno de las tolas. Está claro que todas las informaciones no han sido interpretadas, pero esta síntesis ofrece ya la posibilidad de medir el alcance de la problemática de los montículos artificiales y del potencial arqueológico descubierto en la llanura occidental de los Andes ecuatorianos.

Una revisión más severa de las diferentes estratigrafías hechas en el transcurso de los seis años de campo nos condujo a reconsiderar las hipótesis de nuestros predecesores y a proponer una nueva modelización de las instalaciones prehispánicas de la región estudiada. Anteriormente señalada por los vestigios, la secuencia de las tolas y de su sustrato indicaba una relativa concomitancia en 
cada nivel de ocupación, marcada por la alternancia de las tefras1, de las fases de abandono y de las épocas de construcción (Guillaume-Gentil, 1998; 1999; 2000; 2008a; 2008b). Estos diferentes hechos se mostraron a veces difíciles de precisar cronológica y espacialmente, puesto que las edades de radiocarbono no brindaban siempre resultados significativos y las cineritas aparecían irregularmente en las zonas inventariadas, arrasadas por la erosión o mezcladas con los terraplenes de las tolas.

Las fechas ${ }^{14} \mathrm{C}$, obtenidas a partir de carbones sacados de contextos seguros, permiten sugerir una relativa sincronía de las ocupaciones sacadas a la luz en cada montículo (fig. 4). Se observan igualmente periodos de transformación general del aspecto de los sitios, que alternan con pequeñas refacciones que no afectan sino rara vez a un montículo. Si bien es difícil certificarlo a causa del intervalo de tolerancia de las fechas de radiocarbono, cada construcción y nueva habilitación de plataforma constituye el ciclo completo de una frecuentación humana, seguida por un abandono temporal, al cual le sucede una nueva explotación. A medida que los resultados del análisis cerámico se afinan, las interpretaciones se precisan. Sin embargo, las limitaciones de los medios de datación impiden proponer relaciones cronológicas exactas. Solo los casos de ruptura espectacular (a veces marcada o sostenida por las tefras), ponen en evidencia una contemporaneidad intersitios de ciertos niveles antrópicos. Las analogías materiales y sedimentarias, evidentemente más aleatorias, han reemplazado el apuntalamiento temporal de probables sincronías.

El estudio de los niveles de ocupación sacado a la luz en cada montículo chocan a veces con la escasez de ciertas informaciones. Aunque excavadas en grandes superficies, las tolas no revelan sino raramente la totalidad de las estructuras que pudieron albergar. Tanto la erosión como las múltiples intervenciones humanas (de ayer y hoy) han tenido consecuencias, borrando incluso las huellas dejadas por las comunidades anteriores (Guillaume-Gentil, 2008b).

Gracias a un registro cuidadoso de los datos de campo, pudimos producir un plano incompleto del acondicionamiento descubierto en las plataformas. A pesar de estas aproximaciones, numerosas recurrencias fueron observadas, que conciernieron al esqueleto de las cabañas (elipsoidales), así como a la distribución y forma de los fogones. A fin de precisar mejor las actividades que se desarrollaron en estos suelos, examinamos las concentraciones de cerámica y su asociación con las estructuras descubiertas. De esta forma, intentamos determinar si la forma definía la función o si esta última contenía varios tipos de recipientes $-\mathrm{O}$, al contrario, si algunas funciones se realizaban por medio de una sola variedad de objeto-.

La modelización de las instalaciones monticulares prehispánicas de la llanura de los Andes occidentales está entonces concluida. Pone en evidencia las informaciones espaciales que revelan modelos regulares (simétricos), modelos irregulares y aleatorios (asimétricos), cordones y montículos monumentales, al igual que tolas 


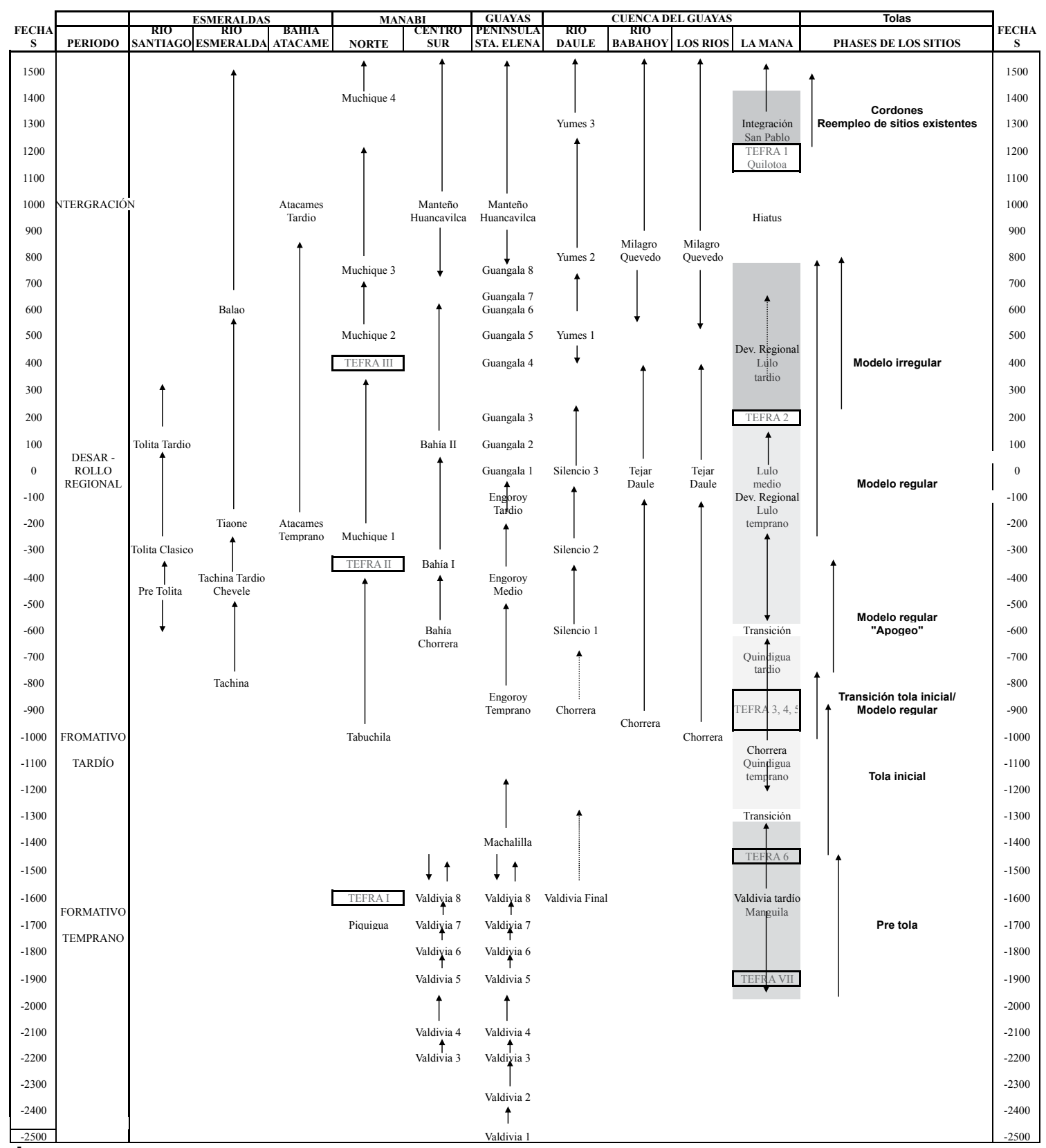

Figura 4 - Tipocronología de los modelos de asentamiento y fases cerámicas de la Cuenca del Guyas en comparación con las otras áreas culturales del Ecuador 
aisladas de dimensiones y situaciones particulares. Estas constataciones pueden ser intercaladas cronológicamente (fases de ocupación de las tolas y modos de explotación, e incluso acondicionamiento de las plataformas, durante los tres milenios de construcción) gracias a siete tefras, 123 fechas de radiocarbono y el análisis estilístico de la cerámica. La complejidad de las marañas de niveles y la tafonomía de ciertos estratos vuelve bastante difícil la interpretación, y aumenta proporcionalmente el replanteamiento de estos últimos.

A pesar de estas reservas, la articulación cronológica de la implantación humana en la región se desarrolla durante cerca de casi cuatro milenios y medio, según las edades de radiocarbono. Unos indicios descubiertos en niveles inferiores hacen suponer la existencia de una población aún más antigua, pero a falta de fósil director fiable, ninguna fecha puede ser otorgada. Hasta casi la mitad del segundo milenio antes de nuestra era (fase pre tola, 2000-1600/1400 a. C.), los habitantes se instalan en terrazas naturales elevadas, bordeadas por un curso de agua. Su hábitat consiste en chozas ovaladas. Las actividades sacadas a la luz revelan prácticas domésticas, pero la función de fosas rectangulares llenas de vestigios no ha sido identificada. A partir del depósito de la tefra VI, es decir durante el periodo tola inicial, los ocupantes acondicionan pequeñas plataformas en las cuales instalan sus moradas; explotan los alrededores habilitando áreas de artesanía y procediendo probablemente a la horticultura (fase tola inicial 1600/1400-950 a. C.). Este nuevo tipo de instalación está igualmente marcado por la aparición gradual de una cerámica cuyo estilo evoca cada vez menos las líneas del Formativo temprano (Valdivia) a favor de facies chorreroides (Formativo Tardío), sin que un paso por Machalilla (Formativo medio) sea necesariamente demostrado. Hacia fines de esta época, parece ser que estas sociedades dominan el tratamiento del metal, tal como lo testimonia la elaboración de estructuras de combustión muy elaboradas (fig. 5). A este desarrollo técnico se suma una importante diversificación en la elaboración de la cerámica y una amplificación de las superficies cultivadas, que necesitan un desarrollo importante de los conocimientos agrícolas.

En lo sucesivo, durante un periodo fuertemente perturbado por erupciones volcánicas (tefra $\mathrm{V}$ a III), una fase de transición tola inicial/modelo regular (1000-800 a. C.) muestra la aparición

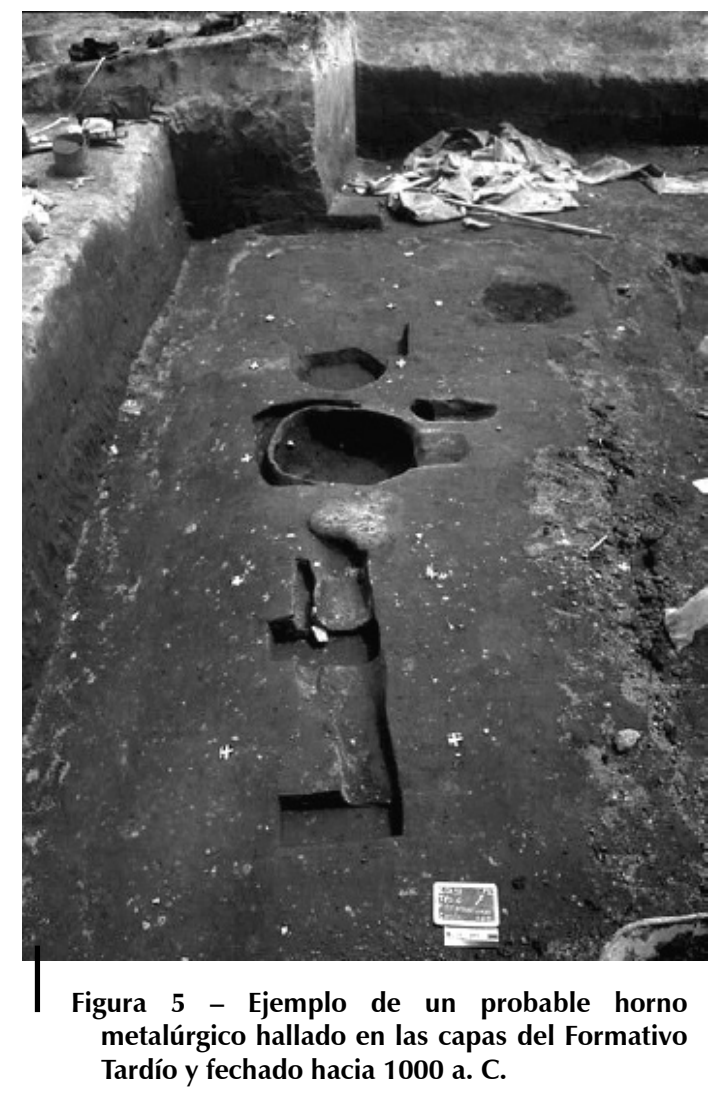


progresiva de montículos cuyo arreglo forma un modelo en «U». En este intervalo, se inicia la edificación de grandes casas, rodeadas por empalizadas que refuerzan muritos de arcilla endurecida. Primero construidas en la loma central, estas moradas se distribuyen poco a poco en los montículos dominantes, contenidos en todas las filas de tolas a excepción de una elevación central en la cual está implantado un espacio ceremonial.

Esta transformación radical del modo de instalación fue denominada «fase de apogeo de los modelos regulares», ya que se trata del periodo durante el cual la multiplicación de las actividades en un mismo sitio es fuerte (fig. 6). Establecido en el desastre de Hallstatt de la curva radiocarbono, este estilo de ocupación es cronológicamente difícil de ubicar. No obstante, la concentración de las edades en el mismo umbral de calibrado y la lenta transición cerámica observada en las estructuras rituales permiten sugerir una sucesión de establecimientos durante 400 a 600 años (800/600 a 300/200 a. C.). En el curso de este mismo periodo, se asiste a una transición en el estilo de las cerámicas, que tendría lugar hacia 600500 a. C., pasando del Formativo Tardío (chorreroide) a la hechura que caracteriza la alfarería del Desarrollo Regional.

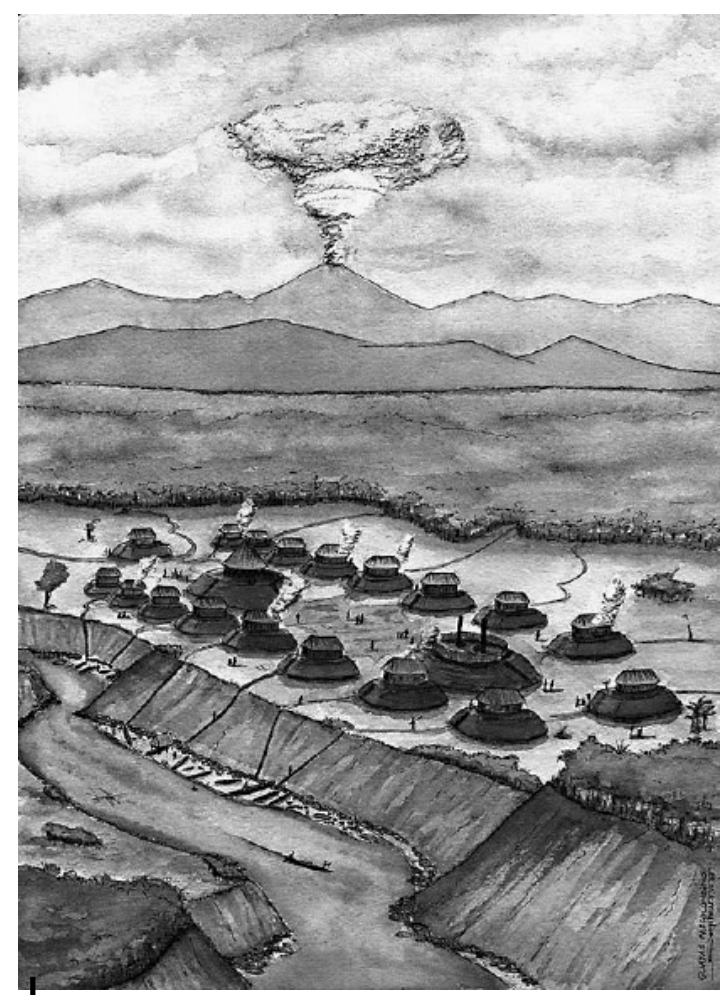

Figura 6 - Acuarela que restituye el modelo regular en su fase de apogeo

Dibujo: S. Rostain
Otro tipo de frecuentación sigue a la fase de apogeo de los modelos regulares. En efecto, la complejidad de los roles concedidos a las tolas se simplifica y rompe con la tradición de los montículos ceremoniales (ninguna huella tangible de práctica simbólica fue identificada en las capas recientes de las tolas perteneciente a un modelo regular). El hábitat se transforma, dando lugar a cabañas elipsoidales bordeadas por áreas artesanales y domésticas. El tiempo de los patrones simétricos, más rudimentariamente explotados y en donde los rituales fueron probablemente desplazados, se despliega entre tres a cuatro siglos (200 a. C.-200 d. C.).

El marcador temporal materializado por la tefra II subraya la aparición de una modificación global de la habilitación del territorio. La fase «modelo irregular» se caracteriza por un hábitat distribuido en las tolas de sitios simétricos, o en terrazas naturalmente elevadas. Al mismo tiempo, las abundantes zonas ceremoniales están establecidas en las tolas que pertenecen a la categoría de patrones asimétricos (modelos irregulares y aleatorios). La 
concomitancia de la frecuentación de los dos tipos de modelos parece en un principio incongruente, pero los elementos sacados a la luz revelan una extensión del área doméstica (nuevo empleo de los sitios simétricos y acondicionamientos en espacios sin montículo), al igual que una especialización del empleo de los grandes montículos perteneciendo a agrupamientos menos ordenados.

Las estratigrafías desvelan un esfuerzo de construcción para las tolas de los sitios asimétricos, en donde se superponen grandes terraplenes en los cuales han sido efectuados rituales. Pocas estructuras de hábitat son visibles en estas lomas, mientras que los modelos regulares se vuelven a emplear con fines domésticos, sin hacer necesariamente una nueva elevación de las lomas. Las terrazas naturales en las cuales aparecen los modelos irregulares contienen numerosos depósitos con restos ligados al simbolismo (estatuillas, recipientes ricamente decorados, etc.), pero también amontonamientos de cerámica mezclados con piedras que llevan huellas de utilización (pigmentos rojos, alisado de las caras, hachas pulidas rotas, recipientes esculpidos, etc.). Así, el periodo de explotación en sí mismo presenta una distribución de los sectores de actividades. Los modelos irregulares y los espacios aledaños parecen destinados a las prácticas ceremoniales o festivas, mientras que los sitios simétricos y los espacios de los alrededores están destinados al hábitat. Iniciándose hacia 200 d. C., este tipo de implantación engloba toda la época del Desarrollo Regional hasta hacia $800 \mathrm{~d}$. C.

Un hiato en la explotación de las tolas ha sido observado, pero está esencialmente ligado a la ausencia de estructuras intactas o de elementos de datación. La presencia de vestigios del periodo de Integración ha sido constatada, pero en contextos muy retocados, descubiertos bajo la tefra I. Además, un breve reconocimiento efectuado en un montículo que forma parte de un modelo de lomas monumentales permite identificar la tefra I en el primer tercio de los terraplenes constitutivos de estas gigantescas elevaciones. Esta constatación induce a una eventual continuidad en la construcción de las tolas, pero siguiendo un acomodamiento distinto. A este indicio se suman los modelos no excavados (tola aislada) susceptibles de llenar el hiato en cuestión.

El levantamiento de las lomas artificiales se perpetúa, ya que es nuevamente comprobado hacia el siglo XIII, época en la cual unos cordones a veces muy largos (más de $600 \mathrm{~m}$ ) están acondicionados en los suelos cubiertos por la tefra I. El rol destinado a estas construcciones no ha sido determinado, pero se asemeja más a actos simbólicos que a funciones agrícolas o domésticas.

Finalmente, procedentes de capas situadas encima de la tefra I, profundas intrusiones perforan los estratos más antiguos de los montículos existentes. Estas intrusiones se terminan generalmente en uno o dos murillos de piedra cuidadosamente ordenados, sin asociación de objeto diagnóstico. Saqueadores de la región mencionan la existencia de tumbas con cámara lateral; es entonces posible que los muritos descubiertos en nuestras excavaciones indiquen la presencia de este género de estructura. Sin embargo, ninguna sepultura ha sido identificada en su perímetro. Inclusive si las perturbaciones no aportan informaciones funcionales, prueban que las lomas han sido aún explotadas más allá del siglo XIII. Estas informaciones de 
segunda mano pueden explicar la confusión de nuestros predecesores, quienes han considerado las tolas de la región como lomas funerarias. Por analogía con la tradición de las «tumbas en chimeneas», característica de los montículos del periodo de Integración en las regiones meridionales de la Cuenca del Guayas, los investigadores de la época han pensado estar frente a un mismo tipo de yacimiento, sin sospechar la amplitud del fenómeno de las tolas de la zona septentrional de la misma cuenca (Guillaume-Gentil, 2007).

El análisis de la cerámica del Formativo temprano, y de la cual presentamos los rasgos generales a continuación, permite matizar y clarificar ciertas sugerencias.

\section{TIPOCRONOLOGÍA REGIONAL}

\section{1. Obtención de la muestra analizada}

Realizadas las excavaciones, el análisis del gran bagaje de cerámica recolectada se convertía en un verdadero reto, con más de ciento cincuenta mil fragmentos cerámicos hallados en todas nuestras temporadas de campo. En la práctica constituía unas nueve toneladas de material cerámico, punto de partida para nuestra investigación, al intentar estructurar una primera secuencia cronológica en esta zona tan poco estudiada.

Hacer una tipología regional, sin el apoyo de investigaciones anteriores para contrastar nuestras investigaciones, complicó nuestra labor, ya que debíamos enfrentar muchos interrogantes planteados y en muchos casos asumidos como reales, pero nunca comprobados completamente. Así pues, la Cuenca del Guayas, según la visión histórica del origen de la alfarería prehispánica ecuatoriana se convirtió en uno de los posibles focos de creación, dispersión o de paso de la misma. Sin embargo nunca hubo clara evidencia de esta propuesta, ya que siempre estarían ocultados por la posibilidad de que la fuerte sedimentación en esta cuenca hidrográfica los mantenga por debajo de varios metros de profundidad, y no permita un hallazgo tan fácilmente como en otras zonas costeras de menor sedimentación.

Por otro lado, una problemática igualmente desconocida es el temprano y complejo comercio que enlaza el litoral (Cuenca del Guayas) con la región andina en centurias de contactos e intercambio que provee un sinnúmero de bienes exóticos a cada región. Este proceso aceptado por toda la evidencia de los bienes comerciados no se puede ligar nítidamente a poblados en la cuenca de Guayas. Siendo pasos obligados, las rutas y los pueblos que los frecuentan, sugieren una complejidad social que todavía no se puede identificar ni modelizar.

Para enfrentar estas problemáticas a lo largo de los 5000 años de presencia cultural en la cuenca norte del Guayas y hacer una lectura a través de su cerámica, se necesitó encontrar una técnica apropiada para registrar las observaciones de esta secuencia y antes que todo sin salir de la estrategia planificada que nos permitió un estudio multidisciplinario del material recogido (Guillaume-Gentil, 2008a; 2008b). 
Los numerosos vestigios cerámicos, no permitieron, en esta primera instancia, realizar un análisis exhaustivo del mismo, sino que dejó el terreno preparado para que estudios futuros sigan la investigación. Se procedió a puntualizar la investigación en los atributos diagnósticos existentes en la muestra, lo que nos restringió a aquellos fragmentos que permitían reconstruir total o parcialmente la silueta de las vasijas a estudiar, seleccionando así las piezas necesarias para describir la variabilidad existente en cada complejo. Se limitó a un estudio morfológico/ decorativo de su alfarería a través de la historia en el sector, centrándose en el mejor de los casos en las vasijas que procedían de contextos seguros. Gran parte del material, en particular cuerpos cerámicos, al no proporcionar información necesaria para esta clasificación, fueron excluidos de este trabajo.

Esta selección se restringió a ocupaciones antrópicas estrictamente identificadas, lo que brindó un importante ahorro de tiempo, ya que al estudiar montículos construidos con múltiples capas de relleno y, por lo tanto incluyendo fragmentos cerámicos mezclados, simplemente se los desechó de este análisis, sin alejarse por esto de una muestra significativa de la evolución cultural y estilística regional.

La «tarea prioritaria» del análisis fue la reconstrucción de las formas ligadas a rasgos y a niveles ocupacionales de los sitios; esta elección es indispensable por dos razones:

- para continuar la elaboración de una base de datos formal/estilística de la cerámica en el norte de la Cuenca del Guayas;

- para asegurarnos de que solo un mínimo de interferencias esté presente al momento de elaborar la reconstitución de las actividades ocurridas en los montículos, evitando cualquier evento de mezcla durante las interferencias que realizamos (Guillaume-Gentil, 2002).

Esta etapa necesitó esperar las conclusiones del estudio estratigráfico de cada tola, para unir con precisión los rasgos con su capa de ocupación respectiva. Por ende, tuvimos una muy evidente correlación de depósitos en nuestra área de estudio. Esta fue realizada a partir de las descripciones sedimentarias de las capas, fechas ${ }^{14} \mathrm{C}$ y eventos volcánicos ya reportados, logrando destacar contextos seguros, permitiendo una división cultural del sitio y la separación clara entre el material hallado en rellenos y aquel sacado de los pisos arqueológicos.

\section{2. Variación formal}

Cada vasija analizada tiene una función primaria, la que tiene íntima relación con su elaboración, tanto formal como de fabricación, por lo cual es importante tomar en cuenta sus particularidades (geométricas, altura, diámetro, etc.), para comprender la importancia de cada complejo en totalidad. Esto es muy importante para enfrentar los cuatro complejos cerámicos analizados en este artículo, ya que existen muchas semejanzas entre ellos, presentándose vasijas de igual forma, pero en diferentes tamaños o con sutiles diferencias; éstas se han conservado como «formas tipos» diferentes, ya que funciones diferentes podrían estar implícitas. 
Características que condicionan la relación de la forma y función tienen que ver con lo que mantiene en su interior: si el contenido es líquido o seco, caliente o frío, si el calor se aplica a ellos en el uso, la frecuencia de transportaciones, el acceso o movimiento del contenido en o fuera del recipiente, la duración de los episodios de uso, especialmente en el almacenaje, la distancia en el traslado, etc. (Guillaume-Gentil, en prensa).

Una vía práctica para definir la función consiste en buscar sistemáticamente la relación entre los atributos métricos de los artefactos, por ejemplo la diferencia entre «diámetro de la boca» y «altura total de la vasija». Esta observación permite notar estándares de clases de vasijas que, según información etnográfica, representan una posible función, la cual corresponde íntimamente a la propia morfología de cada vasija (Balfet et al., 1998).

Según los datos obtenidos, podemos dividir la muestra analizada en las siguientes clases:

Plato: las características generales (diámetro y profundidad) de estos recipientes sugieren que pueden usarse tanto para servir alimentos, como tal vez en tareas de procesamiento que involucran el secado, tostado o resecado de alimentos al fuego (Rice, 2006).

Escudilla: vasija de boca abierta de lados curvos o rectos, pero que, por lo general, tiene la forma de una media esfera. Su diámetro se encuentra entre 12 y $23 \mathrm{~cm}$ y de acuerdo a su relación diámetro/altura su diámetro es 2 1/2 hasta 5 veces mayor que su alto (Rice, 2006; Balfet et al., 1998). En nuestra muestra podemos encontrar dos variantes: escudilla cuyo diámetro se encuentra entre 12 y $23 \mathrm{~cm}$ y plato hondo con abertura mayor a $23 \mathrm{~cm}$.

Cuenco: recipiente abierto, hondo y ancho (inferior o igual a $18 \mathrm{~cm}$ ); puede ser ligeramente cerrado en apertura y en algunos casos no presenta bordes. De acuerdo a su relación diámetro/altura es 1 1 1/2 a 2 1 1/2 veces más ancho que alto (Rice, 2006; Balfet et al., 1998). Se pueden encontrar tres variantes: cuenco con un diámetro que se encuentra entre 12 a $18 \mathrm{~cm}$; cuenco grande cuya boca tiene entre 19 y $40 \mathrm{~cm}$ de diámetro y fuente que posee un diámetro mayor a $40 \mathrm{~cm}$.

Vaso: recipiente abierto de paredes verticales y poco ancho de boca; su diámetro no supera los $12 \mathrm{~cm}$. De acuerdo a su relación diámetro/altura es 1 1/2 más alto que ancho, o un poco menos que eso. Estos recipientes sirven para recoger y contener líquidos, así como para beber (Rice, 2006; Balfet et al., 1998).

Ollas: recipiente cerrado y globular o más o menos cilíndrico, comúnmente más abultado al centro que en los extremos, de boca ancha, con o sin cuello. Su diámetro mínimo es superior o igual a 1/3 del diámetro máximo. De acuerdo a su relación diámetro/altura es 1 hasta 2 veces más ancho que alto (Rice, 2006; Balfet et al., 1998). Su función se asocia directamente a la cocción de alimentos, pero si observamos mejor vemos que según la altura, el volumen, la dirección y el diámetro del borde puede haber funcionado como un recipiente para el almacenamiento temporal, para transportar, o bien para procesar alimentos (Rice, 2006). Además si una mano o algún utensilio puede introducirse en su interior, se relaciona con actividades que necesitan mirar y manipular el contenido (Rice, 2006: 208). 
En nuestra muestra, las ollas son las más numerosas, pero al mismo tiempo son las que menos información nos brindan de silueta completa, y por no caer en dimensiones subjetivas, no intentamos hallar la relación diámetro/altura y subdividir de mejor forma esta categoría funcional.

A pesar de ello estamos seguros que, según las características de algunos cuellos, ciertas ollas presentan indicios de un uso en la conservación y manipulación de líquidos, es decir son botellas, inferidas por la presencia de cuellos relativamente altos y cilíndricos para evitar el derrame del contenido.

Existen casos especiales que debemos mencionar. Se trata de artefactos que no entran en la categoría «vasijas» ya que no contienen nada, pero sí son importantes en cada uno de los complejos cerámicos analizados. Tenemos por ejemplo: descansanuca, ralladores, figurines, torteros, sellos, ocarinas e instrumentos musicales.

\section{3. Estilo Decorativo}

Además se ha registrado una gama extensa de diseños decorativos que se pueden clasificar en siete estándares estilísticos presentes en la mayoría de las vasijas halladas en la zona. Éstos representan unidades específicas y particulares de cada ocupación. Se les ha asignado un orden alfabético que complementan la ordenación numérica asignada a cada vasija tipo.

Decoración A: pintura blanca total, blanco sobre rojo o blanco y rojo.

Decoración B: pintura iridiscente, por lo general a manera de huellas de dedos, y en menor proporción, en diseños irregulares y únicos.

Decoración C: incisos (una o dos líneas) que recorren el borde de las vasijas sobre una superficie con engobe rojo total muy alisada o pulida.

Decoración D: aplique de representaciones zoomórficas y, en muy pocos casos, antropomórficas, sobre una de las superficies de la vasija.

Decoración E: pintura negativa, en diseños irregulares y únicos.

Decoración F: pintura roja a manera de franjas verticales cortas, mejor conocidas como «pintura a dedos» y en pocos casos bandas horizontales.

Decoración G: calado en distintos diseños, por lo general en triángulos y cruces, exclusivamente en pedestales altos.

Es así que una forma tipo puede presentarse sin decoración o con una o varias variables decorativas. Por ejemplo la «forma 3» que es una vasija sin decoración, puede tener variantes (3a, 3b, 3c, 3d, 3e y 3f): se trata de la misma vasija con decoración distinta. Cuando existe un caso de mayor variabilidad en algún tipo de decoración, lo que sucede comúnmente con la presencia de mayor complejidad en diseños incisos, se aumenta la numeración de esta «forma tipo», apareciendo variables denominadas por ejemplo «forma 3c1». 


\section{4. Definición de complejos cerámicos}

Para no caer en posibles errores y equivocaciones, en cada complejo cerámico descrito aquí, se decidió no utilizar nombres de fases cerámicas ya conocidas (Valdivia, Chorrera, Guangala, Tolita, Milagro, etc.) lo que, sería aceptar de antemano la presencia de unidades cerámicas sin considerar la posible presencia de alguna particularidad regional. Se proponen y defininen los siguientes complejos cerámicos, asegurando con una nueva nomenclatura definir todas las variables únicas de esta región, sin dejar de lado las semejanzas con estilos ya conocidos. Más bien se utilizan nombres de los ríos de la región para permitir una diferenciación con las culturas contemporáneas de otras zonas con el fin de no mezclar los datos durante la elaboración de la tipocronología. Cuando este estudio esté completamente acabado, se podrá intentar una reformulación que quepa más en los estándares comunes, proponiendo quizás rasgos específicos del sector.

Manguila: variante regional del Valdivia final en la cuenca Norte del Guayas (figs. 7-11).

Quindigua: variante regional del Chorrera de la cuenca norte del Guayas, que se diferencia, a su vez, del Chorrera de la cuenca sur del Guayas ${ }^{2}$ y por ende de todas las variantes costeras de esta sociedad (Engoroy, Tabuchila, etc).

Lulu: representante cultural del Desarrollo Regional en la cuenca norte, ya que el conjunto cerámico típico de esta época no es conocido completamente. Es más, es muy difícil determinar en la actualidad, según la bibliografía existente, el grupo humano que ha vivido en esta zona.

San Pablo: representaría el Periodo de Integración, específicamente el complejo Milagro Quevedo, el menos estudiado por nosotros, cuyos vestigios culturales son los más escasos de toda la secuencia ocupacional en nuestra investigación y, por lo tanto, del que menos se posee la información necesaria para verificar o no características únicas de esta unidad cerámica en la región.

\section{5. Ocupación Formativo temprano final y Complejo Manguila}

Desde que se publicaron las primeras descripciones de la subfase Valdivia $\mathrm{D}^{3}$ en sitios cercanos a Posorja, es decir a sectores más periféricos de la península de Santa Elena y más cercanos al Golfo del Guayas, se destacó que este material parecía haber tenido un desarrollo distinto al del Valdivia tardío del sitio epónimo (junto al mar y más temprano), sin profundizar cuáles fueron estas diferencias. Ellos también destacaron que muy comúnmente los niveles valdivia $\mathrm{C}$ de la Península

2 Observación personal realizada por Rosalba Chacón, que analiza el material del Formativo Tardío del norte de la ciudad de Guayaquil, sitio Samanes.

3 Hill (1975) reclasifica esta información encasillando a este material como Valdivia VIII. 


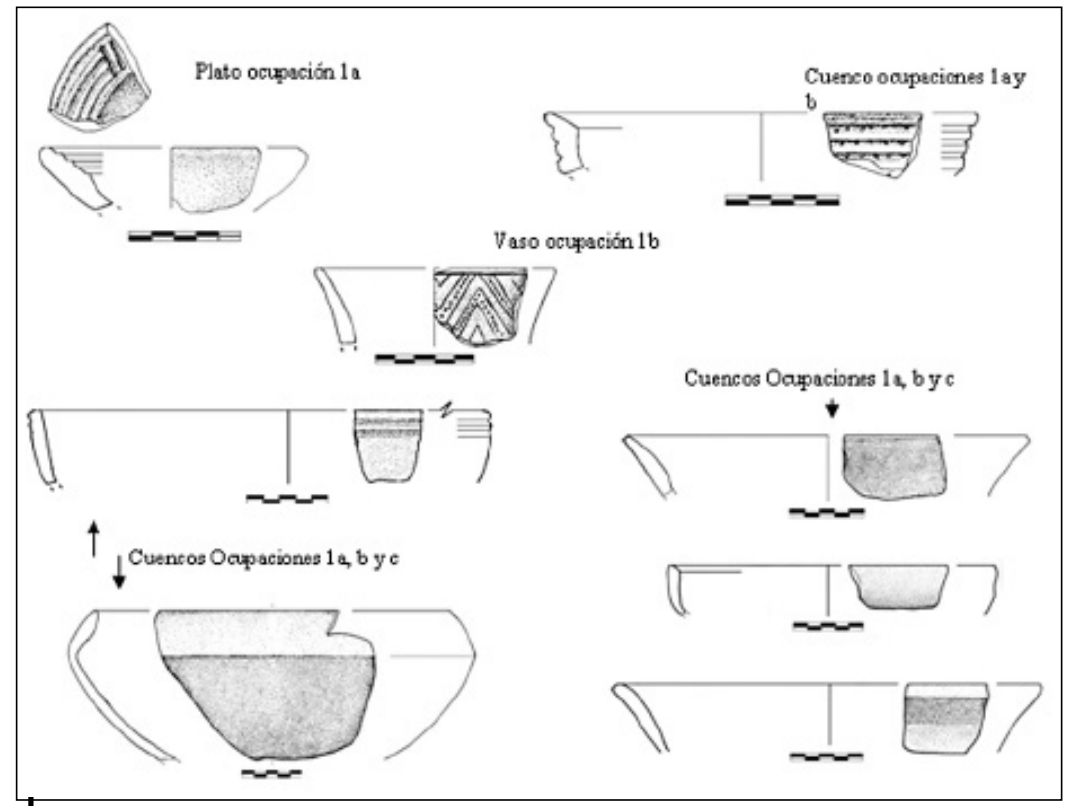

Figura 7 - Vasos y cuencos del Formativo temprano final encontrados en las excavaciones del proyecto

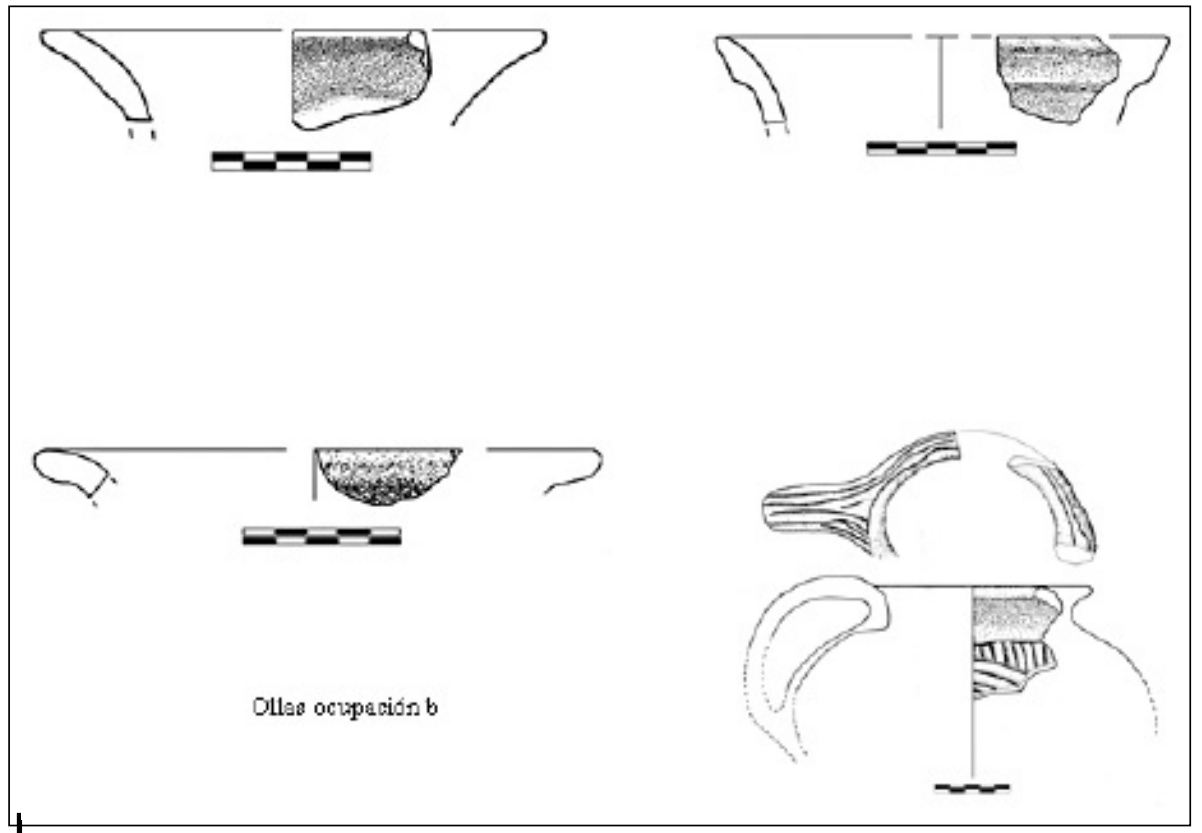

Figura 8 - Ollas de ocupaciones tempranas encontradas en el proyecto

Nótese que no hayamos este tipo de forma en la primera fase de asentamiento humano, al contrario de los vasos, cuencos y botellas que aparecen alrededor de 1400 a. C. 


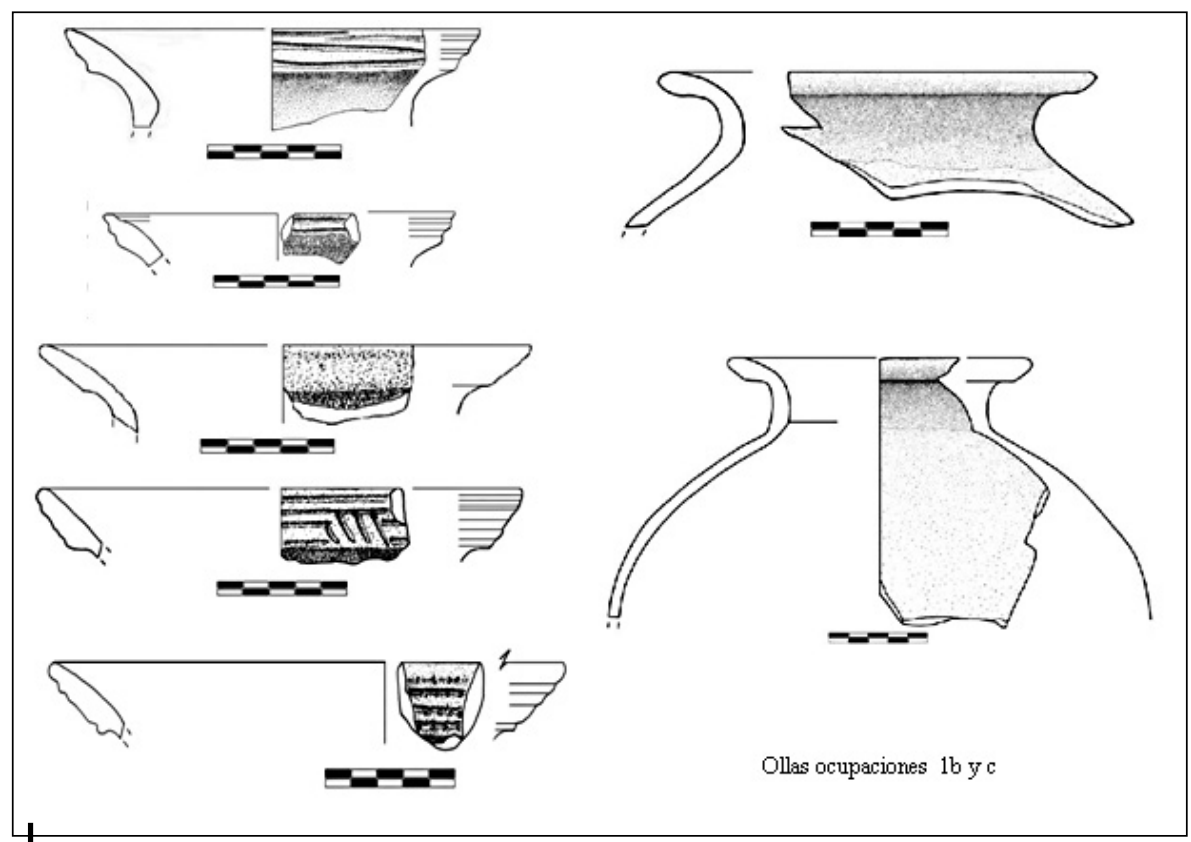

Figura 9 - Ollas de la fase media de las ocupaciones más tempranas entre 1400 y 1250 a.C.

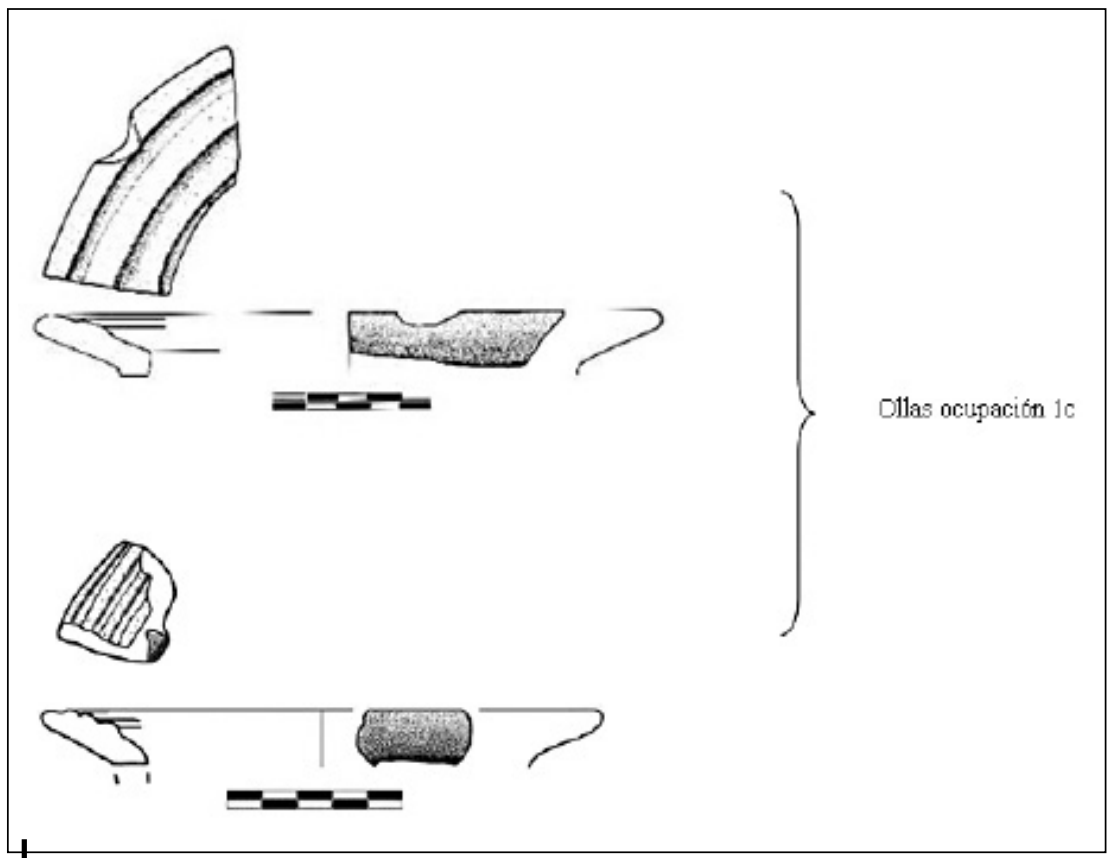

Figura 10 - Ollas de la última fase del Formativo temprano final que podría pertenecer a una fase VIII regional o fase IX 


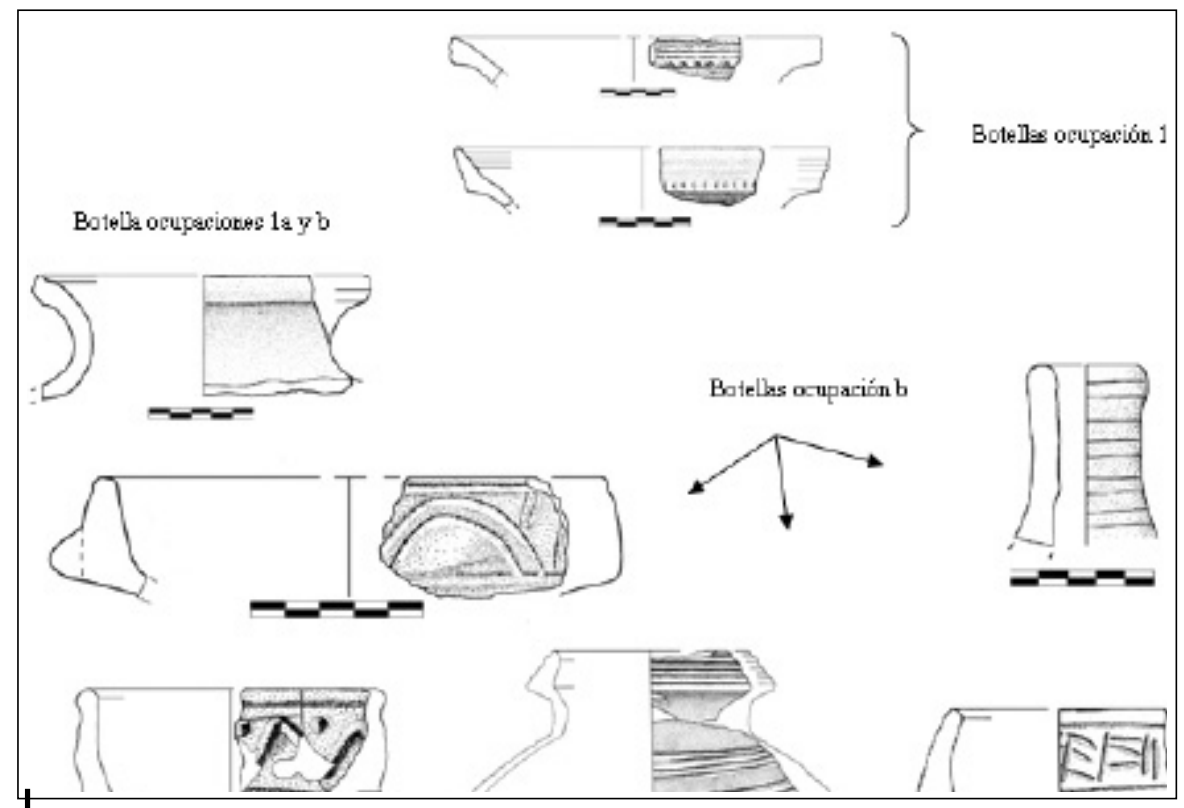

Figura 11 - Botellas halladas en los niveles tempranos de nuestras excavaciones y que presentan semejanzas con otros grupos Valdivia, así como características específicas de la región estudiada

se encontraron mezclados con material Machalilla, infiriendo muy tenuemente una contemporaneidad (Meggers, 1965; Marcos, 1999).

Bischof (1975a) reafirma esta impresión, haciendo notar que los sitios en que se documenta cerámica $C$ y $D$, esta se encuentra mezclada con las fases Machalilla 2 a 4. Esta mezcla implicaría 600 años de relación intensiva sin aculturación clara en su cerámica.

En Real Alto ya se había notado una íntima relación con el material Valdivia D o fase VIII según Hill (1975), concordando con las varias exploraciones llevadas adelante en el valle de Chanduy desde 1967, donde fue hallada gran cantidad de sitios menores Machalilla y Valdivia VIII (Marcos, 1999).

En la prospección arqueológica realizada en 1976, en la cuenca del río Daule, entre Balzar y Daule, se encontró una larga secuencia que se iniciaba con la ocupación Valdivia I/II, a 7,5 m de profundidad (Raymond et al., 1980)4. Sin embargo, para fines del proyecto fue más interesante recalcar que los investigadores notaron la presencia superficial de gran cantidad de material Valdivia VIII, y claramente de mayor riqueza y complejidad de diseño que los hallados en el litoral marítimo de las provincias de Manabí y Guayas (Marcos, 1999). Ya para esta época se conocían

4 Es discutible este hallazgo ya que no ha existido recurrencia en este sentido en la zona. 
los hallazgos en San Isidro (por lo general de múltiples huaqueros y luego gracias a Zeidler [1994]). Posteriormente se empezó a conocer el sitio San Lorenzo del Mate (Cruz \& Holm, 1982 in Staller, 1999; 2000; 2001a; 2001b; Marcos, 1999), Loma de Terán, en San Pedro (Bischof, 1979) y finalmente la Emerenciana en El Oro (Staller, 1996; 1998).

El complejo cerámico Jelí (representante Valdivia final del sitio La Emerenciana), una de las muestras más completas y mejor estudiadas del Valdivia final en el país, tiene la mayoría de las características cerámicas presentes en nuestro complejo. Ahí están, especialmente, toda la variedad de ollas globulares, con bordes muy característicos que son los más representativos de nuestro complejo. Tenemos también las botellas de picos alargados, solo comunes al sur, cuya presencia es muy escasa en la cuenca.

El segundo complejo cerámico mejor estudiado es el de Piquigua (representante Valdivia final del sitio San Isidro) donde, a pesar de hallarse también vasijas comunes con nuestro complejo, no existe una semejanza tan representativa. En su mayoría son botellas, ollas y platos decorados con escisiones anchas, más representativos del Valdivia final de la Costa, incluyendo Península y Manabí, lugar de donde provendría esta influencia formal y decorativa.

Sin ninguna duda, los primeros intentos comprobados de poblar la Cuenca del Guayas se remontan a la fase Valdivia temprano. Sin embargo, las huellas más nítidas se multiplican desde su fase VI, lo que corresponde a la fase Valdivia medio tardío. Culturas contemporáneas a la ocupación Manguila se hallan muy esparcidas, como hemos notado en el resto de la costa ecuatoriana; casi todas se encuentran junto al mar. Al interior de la Cuenca del Guayas se reportan evidencias como ya mencionamos en Daule (Stemper, 1993), en Peñón del Río (Marcos, com. pers.) y ahora en La Maná. Ninguno de los casos, excepto el último, ha sido analizado completamente.

Es relativamente fácil acceder a la descripción de las excavaciones de todos los sitios donde se documenta Valdivia VIII, pero solo en pocos casos, hay una completa descripción de los hallazgos, lo que reduce el nivel de confrontación de esta información. Eso implica que aún no se ha logrado llegar a consensos concretos sobre esta época de la historia ecuatoriana. Quizás estemos frente a la necesidad valdiviana de la búsqueda de nuevas áreas de ocupación en estas fechas, irradiándose desde la Península, hacia todas las direcciones, estableciendo y reforzando ciertos contactos culturales y posiblemente comerciales con los Andes (Villalba, 1988), o con las estribaciones de la cordillera, paso necesario para ir a ambas regiones. Recordemos que ya se ha establecido el contacto Costa-Sierra, tan tempranamente como al final de la ocupación del sitio Real Alto. En sus extremos más periféricos ya se empiezan a hallar las primeras evidencias de obsidiana en la costa ecuatoriana, coincidentemente asociadas a viviendas Machalilla que, como ya hemos mencionado, parece tener cierta contemporaneidad con la gente de la época Valdivia final (Marcos, 1999). Además se nota cierta interacción cerámica entre ambas. Bischof, al conocer el complejo Manguila y comparar con sus hallazgos en el sitio Loma de Terán en San Pedro, frente al mismo sitio epónimo 
Valdivia, reconoce la alta similitud entre Costa y Cuenca del Guayas y nos reporta una clara evolución en el material con la cerámica Machalilla (Bischof, 1979; com. pers.).

Todo eso nos lleva a proponer que las principales sociedades portadoras de la cerámica Valdivia VIII se encuentran en la Cuenca del Guayas y en los valles interiores del litoral de la provincia de Manabí, Guayas y El Oro. En menor proporción se detectan sitios secundarios de la misma fase en la península, lugar en el que para esta época se evidencia un posible y paulatino abandono (Marcos, 1999: 3).

Se postula que los valdivieros de la fase VIII parten de procesos socioeconómicos que se originan en la Cuenca del Guayas. Se trata de un desarrollo independiente a la tradición peninsular cuya base se ubica en el transcurso del Neolítico acerámico conocido como Vegas, y es por eso que deberían existir fuertes similitudes entre la cerámica terminal Valdivia, en los sitios periféricos de Manabí, Guayas y el Oro, ya que estos formarían parte de la tradición de la Cuenca del Guayas.

Por otro lado se empieza a documentar cierta contemporaneidad entre el Valdivia VIII y Machalilla, tanto que se empieza a verificar la presencia espacial de ambas en los centros de larga ocupación Valdivia en la península y en Manabí Sur, donde se encuentran materiales tradicionales Valdivia VII, junto con materiales de intercambio Valdivia VIII y luego Machalilla. Mientras que en los asentamientos menores, donde moran grupos que mantienen tráficos e intercambios con el interior, se encuentra material Valdivia VIII o Machalilla, con cerámica de intercambio Valdivia VII, fabricada en los centros tradicionales Valdivia del Litoral. Se plantea, por lo tanto, que en la Cuenca del Guayas y en las zonas periféricas del litoral, se deberían encontrar los sitios Valdivia VIII y Machalilla libres de toda mezcla, conservando su posición cronológica correcta (Marcos, 1999: 3-4).

Pero otra tendencia actual empieza a considerar que el Formativo temprano Final presenta una fuerte variación regional, es decir, a pesar de su semejanza puede haber una fuerte diferencia entre ellos, complicando de esta manera el entendimiento de esta fase cerámica (Staller, 2001a; 2001b: 99). Se presenta la posibilidad de la existencia, por ejemplo, de una posible fase IX en la secuencia Valdivia (fase Jelí) que documenta la evolución de la cerámica entre el Formativo temprano y Formativo medio de la costa ecuatoriana que adiciona la presencia de ciertas afinidades morfológicas y estilísticas con la cerámica Kotosh de la montaña peruana (Staller, 1996: 17-19), determinando su variación regional, la íntima relación con el Norte Peruano.

Nuestras ollas V-7 y V-11 (fig. 11, arriba y las tres de abajo) representarían las vasijas estándar en todos los sitios tardíos estudiados. También podríamos decir lo mismo de los figurines, los que se encuentran en un proceso aparente de abandono de su uso, para esta época.

El Complejo Piquigua se encuentra representado en nuestra cerámica, por los platos (Forma V-1), un tipo de botella (Forma V-9) y un tipo de olla (Forma V-13). Asumimos que este material es más representativo de la alfarería manabita que de la de Cuenca (Graber, en este volúmen), excepto la olla muy representativa de Manguila. 
El Complejo Jelí se encuentra representado en Manguila por la botella de pico cónico, en muchos casos asociados a insinuaciones fálicas (Forma V-10), y de igual forma hallado en recolecciones superficiales en Milagro y en las excavaciones de San Lorenzo del Mate. Desconocemos para estos dos últimos sitios la importancia de este tipo de botellas, pero en Manguila no es representativo; sin embargo, en La Emerenciana está aparentemente más diagnóstico. En este sentido asociaríamos a estas botellas la posibilidad de poseer asas de estribo, muy comunes en este complejo, siendo principalmente estas botellas, la base para identificar la influencia Machalilla en el complejo (Staller, 1996: 20).

La cerámica Manguila también presenta características únicas, por ejemplo:

- Forma V-3.1 y V-3.2 y V-6 (fig. 7, ocupaciones 1a, b y c): representan el 36,98\% de todo el complejo de los cuencos abiertos o levemente cerrados, que aunque simples no son documentados fuera de la Cuenca del Guayas 5 .

- Forma V-12 y V-14: olla inflexionada de forma relativamente simple y sin ninguna característica especial, excepto un seudo decorado en su borde. Entre ambas vasijas reflejan el 38,33 \% del complejo y por ende son muy características, pero por su calidad, creemos que debía ser más común en todos los sitios, pero no han sido descrito.

- Forma V-15: olla con decoración en sobre relieve en el borde, que representa el $6,55 \%$ del Manguila. No han sido documentados casos similares en otro sitio, por lo que debe ser considerada como exclusiva de la muestra.

- Forma V-2: similar a cuencos Valdivia VII de la Península y no común en otros sitios Valdivia VIII. Nos hace recordar lo que postulaba Marcos (1999) sobre la posibilidad de hallar cerámica de una u otra fase en un mismo sitio, aunque solo se encuentren 4 fragmentos y no sea representativo de la muestra analizada. La Maná es el único sitio fuera de la península de Santa Elena donde ha sido hallado.

- Forma V-4, V-5, V-8, V-12.1, y V-16: son ollas y vasos únicos representados en su mayoría por un solo fragmento en la muestra. Hacemos hincapié en la olla V-12.1 donde se halla una asa que no tiene nada que ver con las conocidas «botellas con asas de estribo».

- Mencionamos unas bases de pedestales en cuencos de San Lorenzo del Mate, aunque son únicas de ese sitio documentadas la presencia de bases anulares muy bajas en nuestro complejo, específicamente asociadas a las vasijas $V-3.1$ y $\mathrm{V}-3.2$ y $\mathrm{V}-6$.

Como ya mencionamos, cuencos de piedra también son diagnósticos de la zona, lamentablemente la muestra que manejamos sobre estas vasijas es muy reducida; sin embargo está claro que son específicas de la región.

5 En Daule sí fueron reportados (Stemper, 1993). 


\section{CONCLUSIÓN}

Esta presentación a grandes rasgos de nuestro proyecto constituye una muestra mínima de los resultados obtenidos a lo largo de quince años de investigación. Se está acabando ahora el estudio de todos los estilos cerámicos recuperados durante las nuestras excavaciones y con miras a publicar un libro que de cuenta de esta tipocronología. El saber que se dispone de materiales tan antiguos constituye en sî un paso adelante ya que amplía mucho el área de dispersión de la cultura Valdivia. Este trabajo permite restituir los numerosos modos de asentamiento humano a través de los siglos, lo que revela una complejidad jamás inferida hasta ahora.

Sería muy importante proseguir con las investigaciones en esta región a fin de precisar más esta modelización: efectuar sondeos en los modelos identificados mas no excavados, aportaría una contribución útil a estas hipótesis. Sin embargo, el análisis de la cerámica, permite matizar y clarificar ciertas sugerencias emitidas en el presente trabajo. Finalmente, estudios más específicos de los vestigios o las estructuras sacadas a la luz (tipos de fogones y macrorrestos contenidos en su relleno, por ejemplo) favorecerían un conocimiento siempre más detallado de las realidades que se ha intentado restituir.

\section{Referencias citadas}

BALFET, H., FAUVET-BeRTHELOT, M.-F. \& Monzon, S., 1981 - Lexique et typologie des poteries. Pour la normalisation de la description des poteries, 146 pp.; París: Presses du CNRS.

BISCHOF, H., 1975 - El Machalilla temprano y algunos sitios cercanos a Valdivia (Ecuador). In: Estudios sobre la Arqueología del Ecuador: 39-67; Bonn: KAVA, Bonner Amerikanistische Studien 3.

BISCHOF, H., 1979 - San Pedro und Valdivia - Frühe Keramikkomplexe an der Küste Südwest-Ekuadors. In: Beiträge zur allgemeinen und vergleichenden Archäologie: 335-389; München: KAVA. Beiträge zur allgemeinen und vergleichenden Archäologie 1.

ECHEVERRÍA ALMEIDA, J., 1983 - Los primeros poblados. In: Nueva historia del Ecuador. Época aborigen, vol. 1 (E. Ayala Mora, ed.): 181-222; Quito: Grijalbo, Corporación Editora Nacional.

GUILLAUME-GENTIL, N., 1996 - El fenómeno de las tolas en la Cuenca norte del Guayas, Ecuador: Nuevas perspectivas. In: Boletín de la Misión Arqueológica Andina: 153-172; Varsovie: Universidad de Varsovia (Andes 1). Actas del III congreso Latinoamericano de la Universidad de Varsovia, Materiales del Simposio sobre los problemas de cronología cultural del área Centro-Andina. 
GUILLAUME-GENTIL, N., 1998 - Patrones de asentamiento en el piemonte andino, en la alta cuenca del río Guayas: proyecto La Cadena-Quevedo-La Maná, Ecuador. In: El Área Septentrional Andina: Arqueología y etnohistoria: 157-206; Quito: Abya-Yala (Biblioteca Abya-Yala 59).

GUILLAUME-GENTIL, N., 1999 - Les tolas du nord du bassin du Guayas : éléments de chronologie et modèles d'occupation. In: Actes des Journées d'études d'archéologie précolombienne : Amérique du Sud, des chasseurs-cueilleurs à l'Empire Inca: 107128; Oxford: BAR International Series 756. Genève, 10 et 11 octobre 1997.

GUILLAUME-GENTIL, N., 2000 - Articulation chronologique de la construction d'un site à tolas (monticules artificiels) grâce à un indicateur géologique: les téphras. In: Actes des journées d'étude de la Société Suisse des Américanistes: 25-54; Genève et Neuchâtel, Société Suisse des Américanistes (Bulletin; 63/1999). Neuchâtel, 12-13 mars 1999.

GUILLAUME-GENTIL, N., 2002 - Los montículos artificiales de la Alta Cuenca del Guayas, análisis cronológico de los modos de ocupación de las sociedades prehispánicas de Ecuador. In: América Latina: Historia y sociedad. Una visión interdisciplinaria: 195214; Barcelona: UAB (Amer \& Cat 7). V años de Aula Oberta de la Universidad Autónoma de Barcelona.

GUILLAUME-GENTIL, N., 2007 - Recherches archéologiques sur les tolas (monticules artificiels) dans le Bassin du Guayas (Équateur). Modes d'implantation, peuplement et chronologie; Neuchâtel: Université de Neuchâtel. Tesis de doctorado (PhD).

GUILLAUME-GENTIL, N., 2008a - Cinq mille ans de préhistoire au pied des volcans en Équateur; Gollion: Infolio-SLSA-FNS (Terra archaeologica VI).

GUILLAUME-GENTIL, N., 2008b - Cinco mil años de historia al pie de los volcanes ecuatorianos, 241 pp.; Quito: Nestlé-SLSA.

GUILLAUME-GENTIL, N., en prensa - Composición y procedencia de la cerámica de las tolas de la alta cuenca del Guayas. In: Actas del simposio sobre arqueometría; Quito: Abya-Yala. Actas del 49 Congreso Internacional de Americanistas, Quito.

HILL, B. D., 1975 - A new Chronology of the Valdivia Ceramic Complex from the Coastal Zone of Guayas Province, Ecuador. Ñawpa Pacha, Vol. 10-12: 1-32; Berkley.

HOLM, O., 1978 - Hachas monedas del Ecuador. In: III Congreso peruano: El hombre y la cultura andina, Vol. 1: 347-369.

MARCOS, J., 1999 - Proceso de neolitización en los Andes ecuatoriales. In: Historia de la América andina (L. G. Lumbreras, ed.): 109-140; Quito: Universidad andina Simón Bolívar, Libresa (Las Sociedades aborígenes 1).

MEGGERS, B., 1965 - Early Formative Period of Coastal Ecuador: The Valdivia and Machalilla Phases, 234 pp.; Washington: Smithsonian Contributions to Anthropology, vol. 1.

PORRAS, P., 1983 - Arqueología del sitio Palenque, Los Ríos. La ponga, Guayas, 238 pp.; Quito: Artes Gráficas Señal (PUCE).

PORRAS, P., 1987 - Nuestro ayer: manual de arqueología ecuatoriana; 326 pp.; Quito: Centro de Investigaciones Arqueológica.

RICE, P. M., 2006 - Pottery Analysis: A sourcebook, 584 pp.; Chicago: University of Chicago Press.

RAYMOND, J. S., MARCOS, J. \& LATHRAP, D. W., 1980 - Evidence of Early Formative Settlement in the Guayas Basin, Ecuador. Current Anthropology, vol. 21, c. 5: 700-701.

STALLER, J. E, 1996 - El sitio Valdivia tardío de la Emerenciana en la costa sur del Ecuador y su significación del desarrollo de complejidad en la costa oeste de Sudamérica (1 ra parte). Cuadernos de Historia y Arqueología, vol. 46-47: 14-37; Guayaquil: CCENG. 
STALLER, J. E, 1998 - El sitio Valdivia tardío de la Emerenciana en la costa sur del Ecuador y su significación del desarrollo de complejidad en la costa oeste de Sudamérica (2da parte). Cuadernos de Historia y Arqueología, vol. 48-50: 65-118; Guayaquil: CCENG.

STALLER, J. E, 1999 - Shamanic Cosmology embodied in Valdivia VII-VIII mortuary contexts from the site of La Emerenciana, Ecuador. In: Mortuary practices and ritual associations: shamanic elements in prehistoric funerary contexts in South America; Chicago: Oxford, BAR International Series. $64^{\text {th }}$ Annual Meeting of the Society for American Archaeology, march 24-28, 1999.

STALLER, J. E, 2000 - Figurines Valdivia VII-VIII del sitio San Lorenzo del Mate, Provincia del Guayas, y la transición Valdivia-Machalilla. Miscelanea Antropológica Ecuatoriana, 9: 99-133; Quito-Guayaquil: Museo del Banco Central.

STALLER, J. E, 2001a - The Jelí phase complex at La Emerenciana, a Late Valdivia site in Southern el Oro Province, Ecuador. Andean Past, 6: 117-174; Nueva York: Cornell University. Latin American Studies Program, vol. 6.

STALLER, J. E, 2001b - Documentando la transición de fase Valdivia a Machalilla con figurines Valdivia VII-VIII del sitio San Lorenzo del Mate, Prov. De Guayas, Ecuador. Cuadernos de Historia y Arqueología, vol. 51-53: 93-179; Guayaquil: CCENG.

STEMPER, D, 1993 - The Persistence of Prehispanic Chifdoms on the Río Daule, Coastal Ecuador; Pittsburg: University of Pittsburg, Department of Anthropology-Quito: Libri Mundi (University of Pittsburg Memoirs in Latin American Archaeology 7).

VILLALBA, M., 1988 - Cotocollao: una aldea formativa del valle de Quito, 571 pp.; Quito: Museo del Banco Central del Ecuador. Miscelánea Antropológica Ecuatoriana (Serie monográfica 2).

ZEIDLER, J. \& PEARSALL, D., 1994 - Arqueología del Norte de Manabí, Ecuador, vol. 1. Medioambiente, Cronología Cultural y Subsistencia Prehistorica en el Valle del Río Jama; Pittsburg, Quito: University of Pittsburg, Department of Anthropology, Libri Mundi (University of Pittsburg Memoirs in Latin American Archaeology 8).

ZEVALLOS-MENÉNDES, 1995 - Nuestras Raíces Guancavilcas, 435 pp.; Guayaquil: Casa de la Cultura ecuatoriana, Núcleo del Guayas. 